\title{
Influence of macroalgal mats on abundance and distribution of dunlin Calidris alpina in estuaries: a long-term approach
}

\author{
Ricardo J. Lopes ${ }^{1,2, *}$, Miguel A. Pardal ${ }^{2}$, Tiago Múrias ${ }^{1}$, João A. Cabral ${ }^{3}$, \\ João C. Marques ${ }^{2}$ \\ ${ }^{1}$ Centro de Investigação em Biodiversidade e Recursos Genéticos, Campus Agrário de Vairão, 4485-661 Vairão, Portugal \\ ${ }^{2}$ Institute of Marine Research (IMAR), Department of Zoology, University of Coimbra, 3004-517 Coimbra, Portugal \\ ${ }^{3}$ Laboratory of Applied Ecology, CETAV-Department of Biological and Environmental Engineering, \\ University of Trás-os-Montes e Alto Douro, 5000-911 Vila Real, Portugal
}

\begin{abstract}
Estuaries used by shorebirds during the non-breeding season face many types of human pressure, including eutrophication and consequent occurrence of macroalgal blooms. The impact of this phenomenon on the abundance of dunlin Calidris alpina in the Mondego estuary, Portugal, was explored using long-term, monthly time series, between 1993 and 2003. The data series included total macroalgal cover, macroinvertebrate biomass and dunlin abundance. We observed an increase in dunlin abundance during this period that matched the decrease in macroalgal cover, especially since the promotion of management actions in 1998. We suggest that this increase was related to the increase of some of its main prey species, the polychaete Hediste diversicolor and the bivalve Scrobicularia plana. At smaller scales, no effect of macroalgae was observed on the proportion of dunlin that chose to feed in alternative habitats (salinas) during the low tide period. However, there was a small effect of the level of algal cover on the proportion of birds recorded on macroalgae at intermediate levels of coverage (around $25 \%$ of total mudflat area).
\end{abstract}

KEY WORDS: Macroalgae - Eutrophication · Intertidal mudflats - Waders · Estuary · Shorebirds · Dunlin

\section{INTRODUCTION}

For many migratory bird species, estuaries are important habitats used as migratory stopover sites and as wintering grounds. Since they are part of many migratory flyways around the world, the protection and conservation of estuaries is crucial for the maintenance of migratory connectivity for these species (Webster et al. 2002). Most of the species of the suborder Charadrii (waders or shorebirds) are migratory and use intertidal areas as their main feeding areas during migration and winter (del Hoyo et al. 1996).

Macroalgae, especially green macroalgae, are common on intertidal flats around the world (Fletcher 1996, Raffaelli et al. 1998). Their abundance is mainly regu- lated by combinations of 3 main factors: combined nitrogen (nitrate and ammonia), phosphorus and changes in the hydrography of the area (e.g. Reise \& Siebert 1994, Flindt et al. 1997, Martins et al. 2001). However, other factors can also be limiting, such as temperature, sub-optimal light and grazer conditions (Raffaelli et al. 1998).

Increasing human pressure on estuaries results in changes in hydrodynamic and nutrient availability, leading to the eutrophication of many estuaries (Jørgensen \& Richardson 1996, Grall \& Chauvaud 2002, Pardal et al. 2004). Increased growth of macroalgae has been identified as one of the main consequences of eutrophication, with direct and indirect impacts on the estuarine trophic chain (Valiela et al. 1997, Raffaelli et 
al. 1998). These blooms may have significant direct effects on the microbiology and chemistry of the underlying sediments, on the physical environment at the sediment-water interface, on other plants, on benthic invertebrates and on other animals, such as shorebirds, that feed on invertebrate prey found in the intertidal flats (Raffaelli et al. 1998).

Indirectly, the presence of macroalgae can also affect shorebird predation of invertebrates by changing prey density, detectability, or accessibility. Density can be reduced or increased depending on the prey species and conditions (Everett 1994, Lopes et al. 2000, Cardoso et al. 2004), whilst detectability can be reduced by camouflage against the macroalgal mats (Everett 1994). Accessibility may be increased by upward vertical migration of prey, forcing deeper living species such as large bivalves and polychaetes to the sediment surface and increasing their chance of being eaten (Kalejta \& Hockey 1991, Raffaelli et al. 1998). Moreover, the combined presence of macroalgal cover and predation can either attenuate or intensify the effects of each factor on the density of macroinvertebrates (Raffaelli et al. 1998).

The extent to which the distribution and behaviour of shorebirds is altered by this process is not obvious. Depending on the scale, there may or may not be clear responses to this process. Shorebirds may react by developing behavioural adaptations (Metzmacher \& Reiser 1994), although in the Mondego estuary, Portugal, short-term studies found no evidence that the presence of algae affected their feeding behaviour (Cabral et al. 1999). Shorebirds may also respond by selecting specific mudflat areas. In Langstone Harbour, England, macroalgal mats inhibited feeding by most of the studied species (Tubbs \& Tubbs 1980), while in the Mondego estuary, there was little evidence to suggest that the birds changed their feeding areas in response to short-term temporal variation in the abundance of algae (Múrias et al. 1997, 2002). More recently, in Clonakilt Bay, Ireland, significantly higher shorebird abundances were found during winter in areas without macroalgal cover (Lewis \& Kelly 2001). In many cases, general eutrophication of the estuary also enhances the biomass and production of invertebrates in macroalgal-free areas, and this may also affect the distribution of shorebirds (Raffaelli et al. 1998). How the effect of macroalgae on the use of alternative habitats scales to effects on the overall number of birds in the estuary is more difficult to discern since many factors may be determinant for the observed numbers and distributions.

In the present study we used a 9 yr data set to explore whether the presence of algae influences the abundance and distribution of a common estuarine shorebird species, the dunlin Calidris alpina, at differ- ent scales: (1) the total dunlin abundance in an estuary, (2) the proportion of birds feeding in 2 different low tide habitats (intertidal mudflats and salinas) and (3) the proportion of birds feeding in areas with and without macroalgae.

\section{MATERIALS AND METHODS}

Study area. The Mondego estuary $\left(40^{\circ} 08^{\prime} \mathrm{N}\right.$, $8^{\circ} 50^{\prime} \mathrm{W}$ ) is located on the Portuguese Atlantic coast. It is $7 \mathrm{~km}$ long and 2 to $3 \mathrm{~km}$ wide, covers an area of 1072 ha (Fig. 1) and supports a large number of shorebirds during migration and winter, due to a large intertidal benthic macroinvertebrate community (Múrias et al. 1997, Dolbeth et al. 2003, Cardoso et al. 2004). The most common species is the dunlin Calidris alpina, while other species are also important: avocet Recurvirostra avosetta, grey plover Pluvialis squatarola, ringed plover Charadrius hiaticula and kentish plover C. alexandrinus (Múrias et al. 1997, Lopes et al. 2002).

Intertidal flats (227 ha) occur in the south and north arms of the estuary. The south arm (intertidal areas = $134 \mathrm{ha}$ ) is shallow ( 2 to $4 \mathrm{~m}$ during high tide), and, due to siltation in its upstream section, the water circulation is dependent on tides and freshwater input from the Pranto River, an important inorganic nutrient input (mainly nitrogen). The south arm mudflats (Fig. 1) are the main feeding area for shorebirds during low tide. Salinas are the main habitat during high tide and are also used during low tide as alternative feeding habitat. In the north arm, mudflats were artificially formed in 1995, but their importance as alternative low tide habitat is very small, with very low numbers of birds recorded (Lopes et al. 2002).

Seasonal intertidal macroalgal blooms (mainly Enteromorpha spp., but also Ulva sp. and Gracilaria verrucosa) have occurred in both arms during the last decade (Flindt et al. 1997, Cardoso et al. 2004, Pardal et al. 2004), probably due to an increase of nutrients. The estuary supports industrial activities and aquaculture and receives nutrients from 15000 ha of cultivated land (mainly rice fields) (Martins et al. 2001). Algae occurred mainly in the inner areas of the south arm (Fig. 2), from late winter to early summer, when the amount of macroalgae often crashed. Since June 1998, ongoing conservation and management actions have reduced nutrient loadings, increased water circulation and protected a meadow of the seagrass Zostera noltii (a very small patch around $200 \mathrm{~m}^{2}$ ) in the more downstream intertidal mudflat (Verdelhos et al. 2005). Our monitoring scheme was fortunate to record the changes that occurred during this process on macroalgal cover and on the abundance of dunlin. 


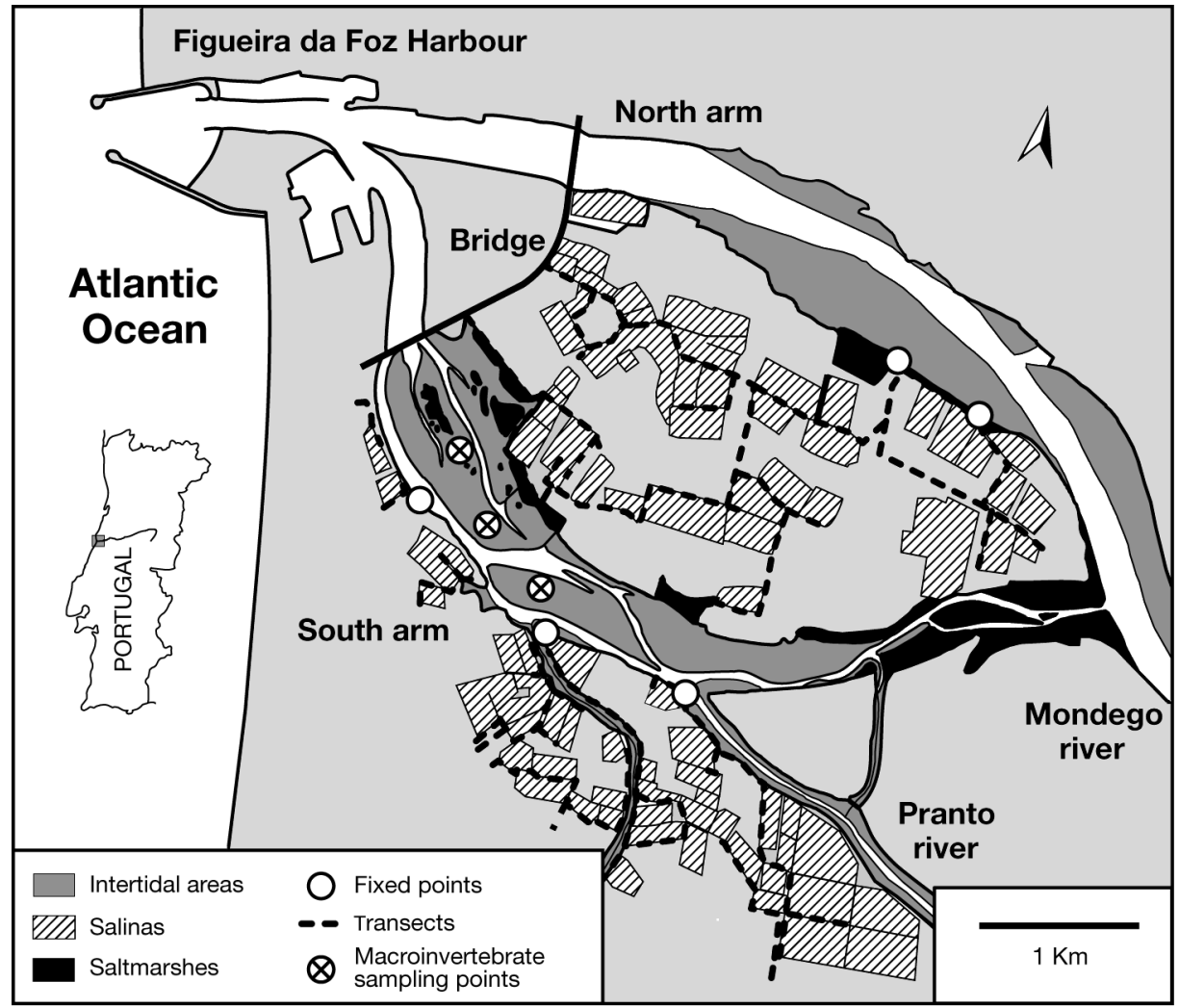

Fig. 1. The Mondego estuary (west coast of Portugal), showing the main types of habitats and the south arm intertidal mudflats that were used as the main study area. The points and transects used for estimating dunlin Calidris alpina abundance and macroinvertebrate biomass are also shown

Dunlin abundance and distribution. From October 1993 to May 1995 and from April 1996 to June 2002, every 2 wk (1993 to 1996) or monthly (1997 to 2002), the total number of dunlins was recorded in a low water census, along with their habitat utilisation and the position of each bird in relation to weed-covered sediments (Múrias et al. 1997, Lopes et al. 2005) The mudflats were surveyed during spring tides from fixed observation points, while a transect (Fig. 1) was used to simultaneously survey the supratidal habitats (mainly salinas). All censuses were performed in 1 (most of them) or 2 consecutive days (one for the mudflats and the other for the salinas), by the same observers.

Area of macroalgal cover. The area of macroalgal cover was estimated, while performing the shorebird counts, by the same observers (Múrias et al. 1997, 2002). The area of weed-covered sediments in most of the intertidal areas of the south arm (total area of $118 \mathrm{ha}$ ) was plotted on separate maps drawn from aerial photographs $(1 \mathrm{~cm}=83.3 \mathrm{~m})$. In order to increase plotting accuracy, the maps included all the identifiable landmarks in the surroundings, including channels, patches of plants, posts and nearby buildings. Area of macroalgal cover was then estimated from the maps using a grid in which each square corresponded to $100 \mathrm{~m}^{2}$.

Macroinvertebrate biomass. The dynamics of the prey items of dunlin were considered to be the most probable explanatory variable to interpret the effect of macroalgae on dunlin. Therefore, long-term sampling of total and specific prey biomass was performed in 3 locations on the south arm mudflats (Fig. 1). Every 2 wk during low tide, at each location, 10 cores $\left(141 \mathrm{~cm}^{2}\right.$ area) were taken to a depth of $15 \mathrm{~cm}$. Each core was placed in a separate plastic bag and sieved through a $500 \mu \mathrm{m}$ mesh sieve. The material retained was placed into plastic bottles and preserved with $4 \%$ formalin in estuarine water. Organisms were identified and counted in the laboratory, and ash-free dry weight (AFDW) was assessed after combustion of samples for $8 \mathrm{~h}$ at $450^{\circ} \mathrm{C}$. A time series was put together using the average value for each sampling date of the mean values of the 3 locations. From the total biomass series we selected 3 species considered to be the main prey items in the Mondego estuary, the gastropod Hydrobia ulvae, the polychaete Hediste diversicolor and the bivalve Scrobicularia plana (Lopes et al. 1998, Cabral et al. 1999). Unfortunately, there is a gap of 3 yr (1996 

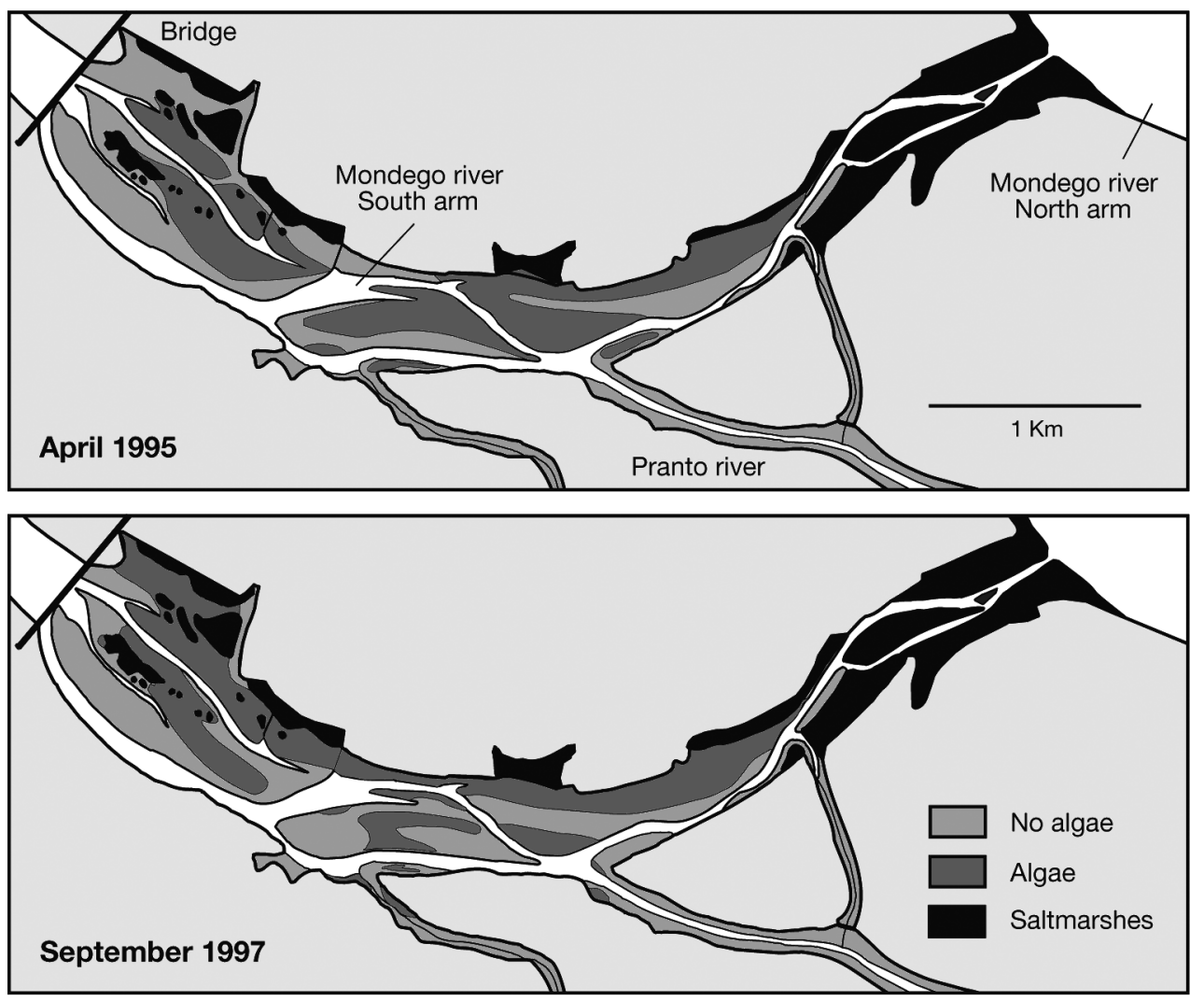

Fig. 2. Illustration of the spatial distribution of macroalgal cover corresponding to the highest values, from 1993 to 2002 . These maps were not used for calculation of areas of macroalgal cover (see 'Materials and methods': Area of macroalgal cover')

to 1998) and longer sampling intervals (monthly or bimonthly) in recent years in the time series, preventing similar analysis comparisons to those used in the other time series.

Long-term trends. A long-term positive trend of dunlin abundance has already been described in a previous article (Lopes et al. 2005). Here, we focused on a comparative analysis of the long-term trends and the impact of management actions in the algal cover time series. Since a seasonal pattern occurred in both series (dunlin and algal cover), non-interrupted monthly time series (1996 to 2002) were first estimated by averaging counts made every $2 \mathrm{wk}$ when necessary and estimating the few missing values by interpolation of the 2 nearest values. Then, both time series were decomposed into 3 additive components (trend, seasonal and residual) using STL (seasonal and trend decomposition with Loess; Cleveland et al. 1990, Chaloupka 2001). The STL procedure is an extension of a class of non-parametric regression procedures known as generalised additive modelling (Hastie \& Tibshirani 1990). This a priori analysis showed a clear distinction between a highly eutrophic system (October 1993 to June 1998), an intermediate system (July
1998 to April 2001) and a less eutrophic system (May 2001 to June 2002). This pattern was taken into account in further analysis.

Non-interrupted complete time series of monthly average algal cover and dunlin abundance data were only available from April 1996 to June 2002 (Fig. 3). To test the null hypothesis that, prior to management actions, the abundance of dunlins in the estuary was not dependent on the extent of macroalgal cover, the functional relationship between the 2 trend components derived from the STL decomposition was evaluated using a generalised least squares (GLS) linear regression (Carrol \& Pearson 2000). This procedure accounted for error autocorrelation using an autoregressive process. This was necessary since individual values were not independent and showed temporal correlation. The trend component of shorebird abundance was transformed (square root transformation) before analysis, due to the Poisson distribution of the count data.

Distribution on low tide macrohabitats. To test the null hypothesis that, prior to management actions, birds chose between low tide habitats regardless of the extension of algal cover on intertidal mudflats, 2 differ- 
ent classes of models were fitted to the proportions of birds that were observed in salinas and intertidal mudflats (dependent variable): a generalised linear model (GLM) and a generalised additive model (GAM). GLMs are more model driven, while GAMs are less restrictive as they allow more flexible response models (Hastie \& Tibshirami 1990). Both models used a quasi- binomial error distribution to take into account overdispersion and logit link function. The GAMs were fitted using penalised regression splines with 4 degrees of freedom (Wood \& Augustin 2002). As a measure of model fit, a coefficient $\left(\mathrm{R}^{2}\right)$, which was the fraction of the total variation accounted for by the model, was used (Begg \& Marteinsdottir 2002).
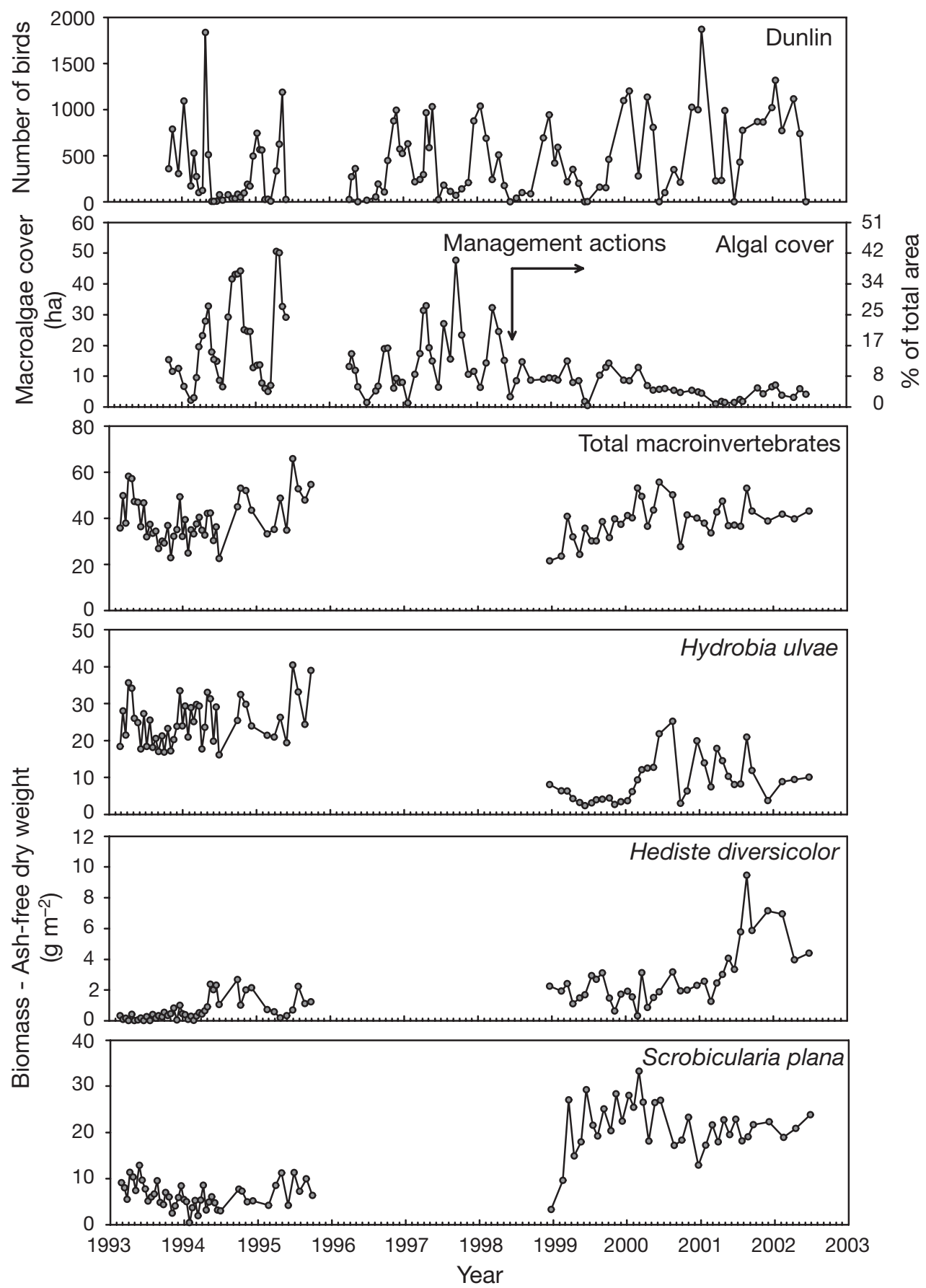

Fig. 3. Temporal dynamics of the abundance of dunlin Calidris alpina, algal cover and macroinvertebrate biomass in the Mondego estuary, from 1993 to 2003. The onset of management actions is indicated with an arrow in the second graph 

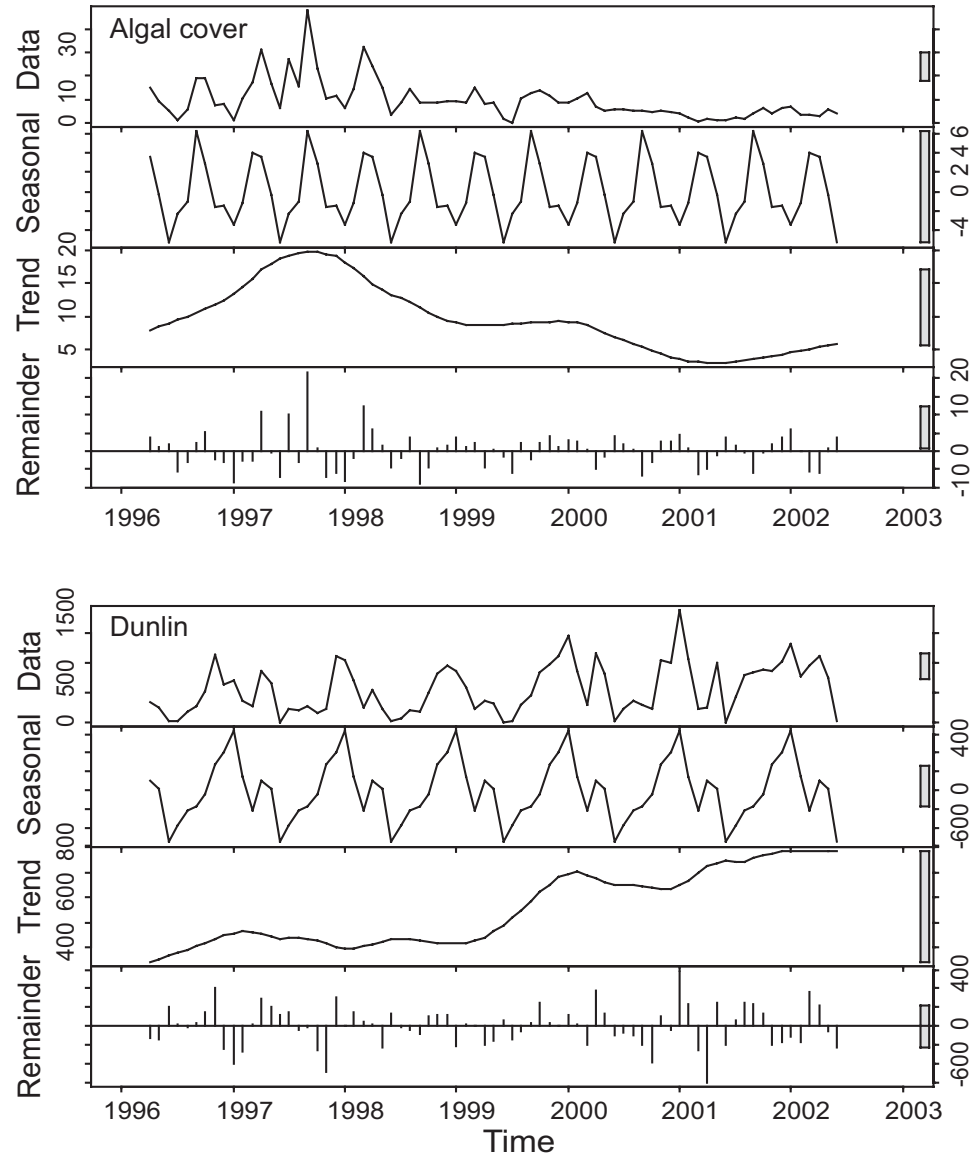

Fig. 4. Seasonal and trend decomposition using Loess (STL) decomposition plots of macroalgal cover (ha) and dunlin Calidris alpina abundance in the Mondego estuary, from 1996 to 2003. The plot scales are not the same, so the vertical bar at the right of each plot indicates the relative variation in scaling amongst the components and the original data series

total intertidal area was represented in a grid $(1 \times 1$ ha squares), and the expected proportions of birds were estimated considering a specific dunlin abundance and algal cover, at which each bird had a random probability of being assigned to a grid square independently of the presence of other birds. Simulations were performed 1000 times using the values of each sampling date and compared to actual observed data. All statistical analysis in this paper was performed using R 1.8.1 software (R Development Core Team 2003).

\section{RESULTS}

\section{Long-term trends}

Over the study period, macroalgal cover varied from zero to a maximum of $43 \%$ total area (Figs. 2 \& 3); was markedly seasonal, especially in dry years (1996 and 1997); and the range of macroalgal cover gradually declined, most probably due to the management activities that decreased nutrient inputs into the estuary (Fig. 3). A slight increase in the area of Zostera noltii meadows has been observed in recent years. Our methodology did not distinguish between both types of cover (algae and seagrass), but only during the later years did the relative importance of seagrass increase on the more downstream mudflats. An increase in the numbers of dunlin Calidris alpina was also

Macroalgal cover was used as an independent variable, and the total abundance of dunlin in the estuary was also included in the models as an independent variable to take into account density-dependent behaviours. All data from 1993 to June 1998 were used.

Distribution on intertidal mudflats. To test the null hypothesis that, prior to management actions, dunlins on intertidal mudflats were not distributed in relation to macroalgal cover, 2 classes of models were fitted to the proportions of birds counted on areas with macroalgal cover and on bare mudflat. As in the earlier analysis, a GLM and a GAM were used (quasi-binomial error distribution to take into account overdispersion and logit link function). Macroalgal cover was used as an independent variable, and the total number of dunlin in the estuary was again included. All data from October 1993 to June 1998 were used.

A spatial simulation of expected proportions of birds in algal-covered mudflats was also performed. The observed, especially from 1999 onwards (Fig. 3), and macroinvertebrates decreased in biomass till 1995, with recuperation during later years, especially in Hediste diversicolor and Scrobicularia plana.

Seasonal decomposition revealed clear and opposing trends in the original time series (Fig. 4). The commencement of management actions coincided with changes in the trends of direction and pattern (Fig. 3). Prior to management actions (1993 to 1998), the trend dynamics in the total abundance of dunlin were not significantly associated with macroalgal cover ( $t$ value $=0.241, \mathrm{p}=0.811$ )

\section{Distribution on low tide macrohabitats}

The GAM and GLM analyses did not explain the variability of the choice of macrohabitat (salinas or intertidal mudflats). In the GAM analysis, effects of macroalgal cover and the total abundance of dunlin in 
the estuary remained stable (Fig. 5) and did not influence the proportion of birds that chose to stay in the salinas at low tide (Table 1).

\section{Distribution on intertidal mudflats}

As above, the GAM and GLM results were similar, although the GAM analysis fitted the data better (Table 2). Macroalgal cover explained most of the variability captured by the GAM (near $35 \%$ ), while dunlin abundance was not significant. According to this model, a significant increase in the proportion of birds in macroalgal habitats occurred with the extension of macroalgal cover.

Simulations indicated no preference or avoidance of macroalgae at a low percentage of cover (e.g. $8 \%$ ), but at an intermediate percentage of cover (e.g. 25\%), there was indication that birds avoided algal-covered areas (Fig. 6). At high macroalgal cover (e.g. 42\%), the size of the confidence intervals prevented further interpretations.
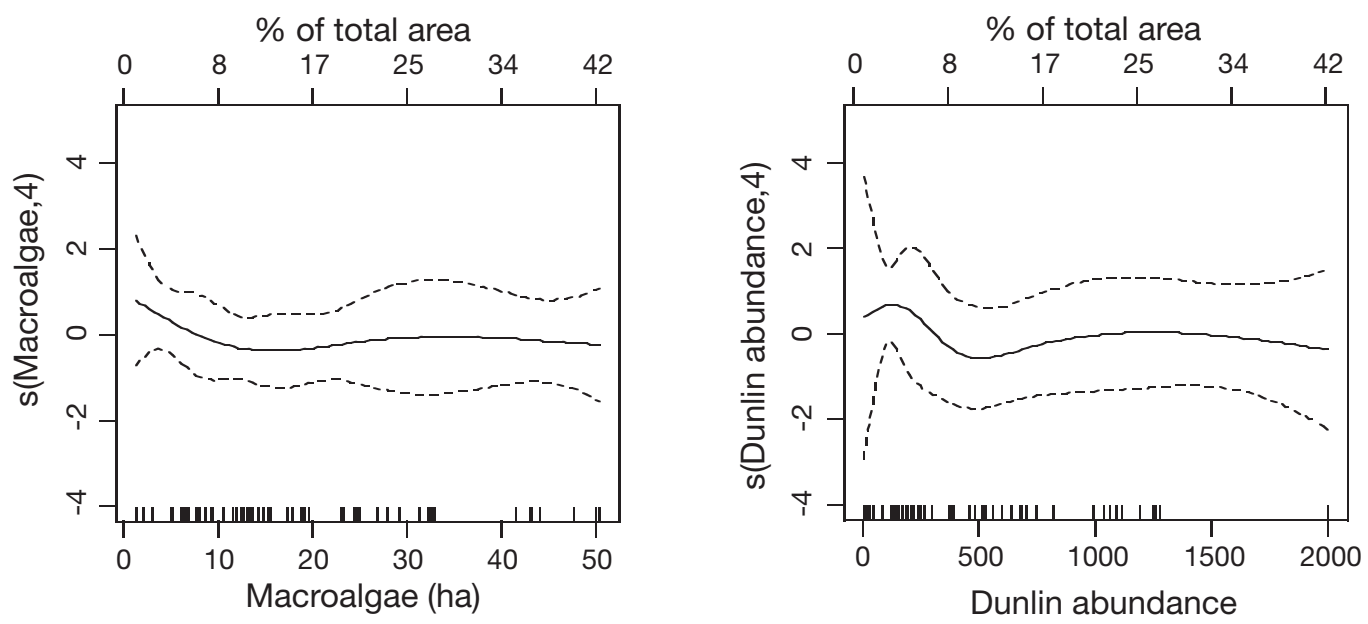

Fig. 5. GAM smoothed terms of the effect of macroalgal cover (ha) and the total abundance of dunlin Calidris alpina on the proportion of birds that were counted at salinas. The rugplot on the $x$-axis represents the number of observations. Dashed lines are $95 \%$ confidence intervals of the smoothed terms. The smoothed terms indicate the relative effect of each explanatory variable on the prediction. The degrees of freedom are also given in the $y$-axis label

Table 1. Models of the effects of macroalgal cover and the total abundance of dunlin Calidris alpina on the proportion of birds that chose to feed at the salinas. The table shows p-values from predictor variables, null and residual model deviance and the pseudo-coefficient of determination $\left(\mathrm{R}^{2}\right)$ for each model

\begin{tabular}{|lcccc|}
\hline \multirow{2}{*}{ Model } & \multicolumn{2}{c}{ Predictor variables $(\mathrm{p})$} & \multirow{2}{*}{ Null deviance } & Residual deviance \\
& Macroalgal cover & Dunlin abundance & \\
\hline GAM & 0.816 & 0.602 & 10978 & 10115 \\
GLM & 0.828 & 0.517 & 10979 & 10858 \\
\end{tabular}

Table 2. Models of the effects of macroalgal cover and the total abundance of dunlin Calidris alpina on the proportion of birds that chose to feed on algal-covered mudflats. The null and residual model deviance and the pseudo-coefficient of determination $\left(\mathrm{R}^{2}\right)$ are shown for each model

\begin{tabular}{|c|c|c|c|c|c|}
\hline \multirow[t]{2}{*}{ Model } & \multicolumn{2}{|c|}{ Predictor variables (p) } & \multirow[t]{2}{*}{ Null deviance } & \multirow[t]{2}{*}{ Residual deviance } & \multirow[t]{2}{*}{$\mathrm{R}^{2}$} \\
\hline & Macroalgal cover & Dunlin abundance & & & \\
\hline \multicolumn{6}{|c|}{ Simulated } \\
\hline GAM & $<0.000$ & 0.834 & 1876 & 8.190 & 0.997 \\
\hline GLM & $<0.000$ & 0.250 & 1876 & 133.2 & 0.929 \\
\hline \multicolumn{6}{|c|}{ Expected } \\
\hline GAM & 0.007 & 0.371 & 10476 & 6818 & 0.349 \\
\hline GLM & 0.001 & 0.139 & 10476 & 8725 & 0.167 \\
\hline
\end{tabular}



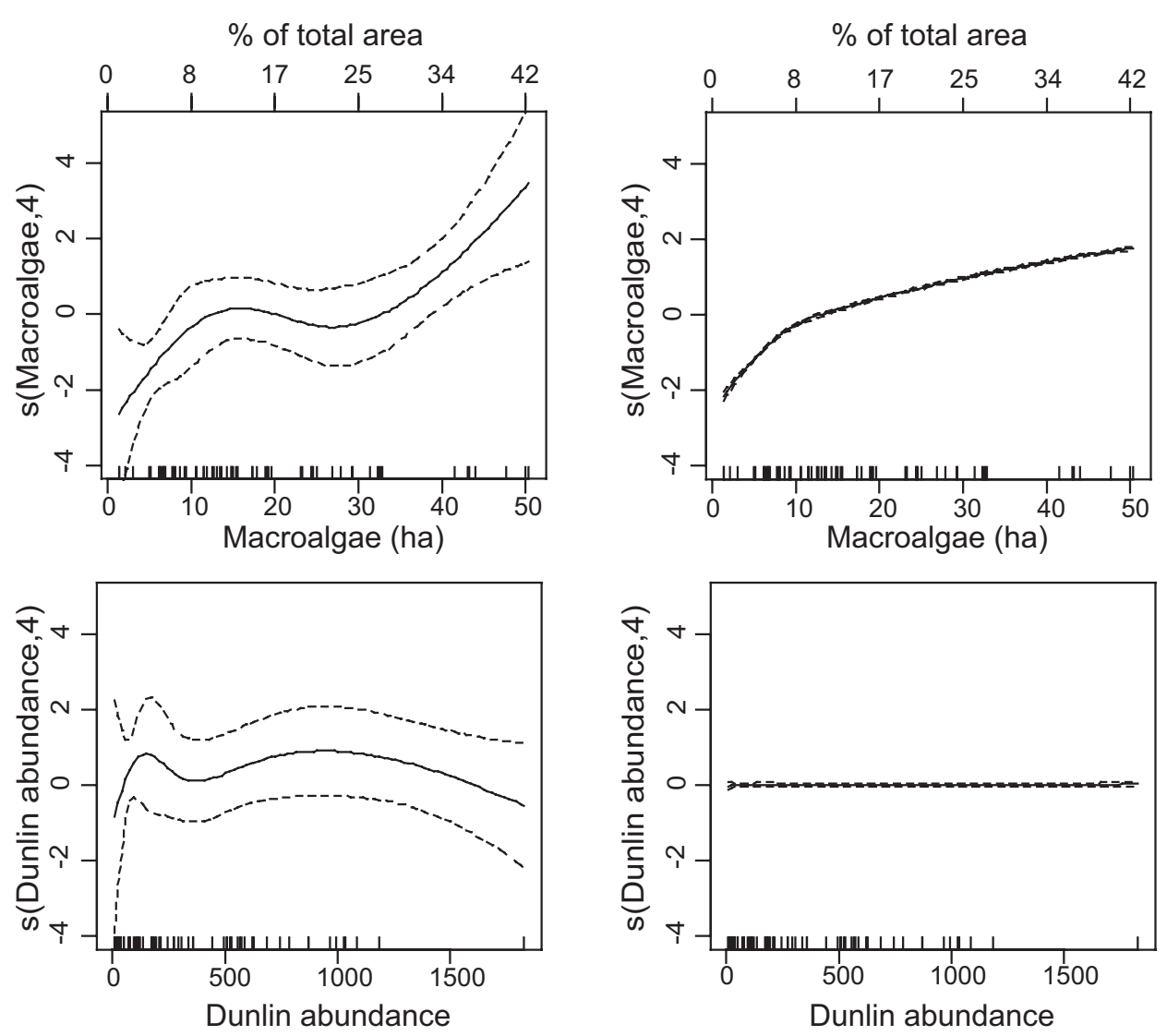

Observed data

Simulated data

Fig. 6. GAM smoothed terms of the effect of macroalgal cover (ha) and the total abundance of dunlin Calidris alpina on the proportion of birds that were counted on macroalgal mats. Two models are represented, based on observed data (left column) and simulated data (right column). The rugplot on the $x$-axis represents the number of observations. Dashed lines are $95 \%$ confidence intervals of the smoothed terms. The smoothed terms indicate the relative effect of each explanatory variable on the prediction. The degrees of freedom are also given in the $y$-axis label

\section{DISCUSSION}

The influence of macroalgal cover on dunlin Calidris alpina distribution on intertidal mudflats was only observed when cover was very extensive, as expected. At lower values of algal cover (e.g. 10 ha), there was no effect on dunlin distribution. For intermediate values (e.g. 30 ha), an avoidance of algal cover areas seemed to occur. Unfortunately, data were insufficient to draw conclusions for very high levels of macroalgal cover (e.g. 50 ha). Short-term, negative effects of algae on dunlin at intermediate cover values may be due to either direct interactions between birds and algae or indirect associations through changes in prey abundance. Microhabitat use on selected plots in the Mondego estuary mudflats from October 1993 to May 1994 also showed a small but significant negative influence of algal biomass on the density of dunlin (Cabral et al. 1999).
Besides the spatial effect (cover), smaller areas of algal mats may have lower impacts on shorebirds and on the underlying macroinvertebrate communities. In Mondego estuary, the coverage of macroalgal mats is highly correlated with algal biomass (Múrias et al. 1996, 2002), and the effect of biomass may be complementary to the effect of size. Unfortunately, with our methodology for the estimation of algal spatial extent (cover), it is not possible to differentiate between areas with different values of macroalgal biomass.

The choice by birds regarding the type of macrohabitat (salinas versus mudflats) was also examined in relation to macroalgal cover; there was no evidence that birds selected the salinas over the mudflats on the basis of macroalgal cover. However, other factors may be important in the selection of mudflat versus salina habitat. Salinas are artificial habitats that are progressively becoming degraded, owing to a decline in their economic value for salt production. This has led to an 
increase in the heterogeneity of abandoned salinas due to variations in water levels, vegetation succession and harvestable biomass. The implications for shorebird abundance are still not clear, but these factors may explain why salinas are not preferred habitats compared to algal-covered mudflats in the Mondego estuary. Múrias et al. (1996) also suggested that dunlin do not switch between different low tide habitats, showing site fidelity.

Dunlin abundance did not show significant association with algal cover dynamics during the period prior to 1998 , when macroalgal blooms occurred. However, the long-term decline in algal cover is clearly associated with increasing dunlin abundance. It would seem, therefore, that dunlin may only respond favourably to a continued decrease in macroalgal cover rather than to variations in cover per month or every $2 \mathrm{wk}$. It has already been shown for the Mondego estuary that the impact of macroalgal cover is cumulative, since continuous cycles of macroalgal blooms can slowly change the macroinvertebrate community throughout the years, while the present situation may increase the macroinvertebrate diversity and other communities (e.g. Zostera noltii meadows) (Pardal et al. 2000, Dolbeth et al. 2003, Cardoso et al. 2004, Verdelhos et al. 2005).

In a previous article, a negative binomial generalised model was fitted to each monthly series of abundance. In all months, the yearly trend was positive, and it was significant in January, the most important month in terms of abundance, and also during summer migration, when the highest peaks of macroalgal cover occurred (Lopes et al. 2005).

The effect of macroalgae on dunlin may not necessarily be direct and effects on prey are likely. The main prey items of dunlin in this estuary are the gastropod Hydrobia ulvae, the errant polychaete Hediste diversicolor and the bivalve Scrobicularia plana (Lopes et al. 1998, Cabral et al. 1999). It might be thought that $H$. ulvae would not be affected on a local scale by the presence of algae, as a result of its mobility and ability to graze algae (Lopes et al. 2000). However, a decrease in abundance was recorded in the last decade, followed by an increase in recent years. As expected, $H$. diversicolor and $S$. plana always presented low biomass in the presence of algal cover. Since mitigation measures in 1998, an increase in biomass has been observed. This could also be associated with the expansion of seagrass meadows (Verdelhos et al. 2005). Because Hediste and Scrobicularia are much larger than $H$. ulvae, they are usually responsible for a high percentage of the biomass ingested by dunlin, and an increase in their availability is probably responsible for the positive trend in dunlin abundance.

Although dunlin have increased on the Mondego estuary, in line with declines in algal cover, up-to-date information on national trends for dunlin (Sousa 2003) and on winter population trends for the east Atlantic flyway (Wetlands International 2002) are not available. However, the Portuguese wintering population remained stable at the most recent assesment in 2000, and the wintering population of the east Atlantic flyway has also been stable for the last decade (Lopes et al. 2005). The mid-winter trends were not significantly correlated between the Mondego estuary and Portuguese estuaries (Lopes et al. 2005). There is nothing, therefore, to indicate that the trends seen on the Mondego estuary are a reflection of wider patterns, and we conclude that they are related to local conditions.

Our results show that the relation between dunlin abundance and macroalgal cover is far from straightforward. Other shorebird species, due to their specific feeding behaviours, may respond in different ways to the presence of weed mats. Dunlin use mainly tactile feeding strategies and rely on sensory organs in the bill to identify prey. Other species, especially from other genera (e.g. Charadrius), use different feeding strategies and may therefore show distinct responses to the presence of algae (Tubbs \& Tubbs 1980, Lewis \& Kelly 2001). Also, density-dependent behaviour and territoriality may be more important in other species. Therefore, one needs to be cautious when extrapolating these results to other species. However, these results are consistent with those from another estuary, the Ythan estuary in Scotland (Raffaelli et al. 1989), where an increase over several years in the abundance of dunlin and other species with nutrient enrichment was noted, although cause-effect relationships were not established. Much remains to be done in this area to provide information for the future management and conservation of estuaries like the Mondego, in order to face the increasing impacts from nutrient enrichment and macroalgal blooms.

Acknowledgements. We thank all the volunteers who helped in the collection of data for the Mondego estuary. We also thank D. Raffaelli, J. Ramos and L. Wennerberg for valuable revisions to the manuscript. This research was funded by Fundação para a Ciência e a Tecnologia (FCT) through Grant PRAXIS XXI/BD/16250/98.

\section{LITERATURE CITED}

Begg GA, Marteinsdottir G (2002) Environmental and stock effects on spatial distribution and abundance of mature cod Gadus morhua. Mar Ecol Prog Ser 229:245-262

Cabral JA, Pardal MA, Lopes RJ, Múrias T, Marques JC (1999) The impact of macroalgal blooms on the use of the intertidal area and feeding behaviour of waders (Charadrii) in the Mondego estuary (Portugal). Acta Oecol 20:417-427

Cardoso PG, Pardal MA, Lillebø AI, Ferreira SM, Raffaelli D, Marques JC (2004) Dynamic changes in seagrass assem- 
blages under eutrophication and implications for recovery. J Exp Mar Biol Ecol 302:233-248

Carrol SS, Pearson DL (2000) Detecting and modeling spatial and temporal dependence in conservation biology. Biol Conserv 14:1893-1897

Chaloupka M (2001) Historical trends, seasonality and spatial synchrony in green sea turtle egg production. Biol Conserv 101:263-279

Cleveland RB, Cleveland WS, McRae JE, Terpenning I (1990) STL: a seasonal-trend decomposition procedure based on Loess. J Official Stat 6:3-73

del Hoyo J, Elliott A, Sagatal J (1996) Handbook of the birds of the world, Vol. 3. Hoatzins to Auks. Lynx Edicions, Barcelona

Dolbeth M, Pardal MA, Lillebo AI, Azeiteiro U, Marques JC (2003) Short- and long-term effects of eutrophication on the secondary production of an intertidal macrobenthic community. Mar Biol 143:1229-1238

Everett RA (1994) Macroalgae in marine soft sediment communities: effects on benthic faunal assemblages. J Exp Mar Biol Ecol 175:253-274

Fletcher RL (1996) The occurrence of 'green tides' — a review. In: Schramm W, Nienhuis PH (eds) Marine benthic vegetation: recent changes and the effects of eutrophication. Springer, Berlin, p 743

Flindt MR, Kamp Nielsen L, Marques JC, Pardal MA and 5 others (1997) Description of the three shallow estuaries: Mondego River (Portugal), Roskilde Fjord (Denmark) and the Lagoon of Venice (Italy). Ecol Model 102:1731

Grall J, Chauvaud L (2002) Marine eutrophication and benthos: the need for new approaches and concepts. Global Change Biol 8:813-830

Hastie TJ, Tibshirani RJ (1990) Generalized additive models. Chapman \& Hall, London

Jørgensen BB, Richardson K (1996) Eutrophication: definition, history and effects. In: Jørgensen BB, Richardson K (eds) Eutrophication in coastal marine ecosystems. Coastal and estuarine studies, Vol. 52. American Geophysical Union, Washington, DC, p 120

Kalejta B, Hockey PR (1991) Distribution, abundance and productivity of benthic invertebrates at the Berg River estuary, South Africa. Estuar Coast Shelf Sci 33:175-191

Lewis LJ, Kelly TC (2001) A short-term study of the effects of algal mats on the distribution and behavioural ecology of estuarine birds. Bird Study 48:354-360

Lopes RJ, Cabral JA, Múrias T, Marques JC (1998) Contribuição para o conhecimento da dieta do Pilrito-comum Calidris alpina e da Tarambola-cinzenta Pluvialis squatarola no Estuário do Mondego. Airo 9:27-32

Lopes RJ, Pardal MA, Marques JC (2000) Impact of macroalgal blooms and wader predation on intertidal macroinvertebrates: experimental evidence from the Mondego estuary (Portugal). J Exp Mar Biol Ecol 249:165-179

Lopes RJ, Cabral JA, Múrias T, Pacheco C, Marques JC (2002) Status and habitat use of waders in the Mondego estuary. In: Pardal MA, Marques JC, Graça MAS (eds) Aquatic ecology of the Mondego river basin. Global importance of local experience. Imprensa da Universidade de Coimbra, Coimbra, p 219-230

Lopes RJ, Múrias T, Cabral JA, Marques JC (2005) A ten year study of variation, trends and seasonality of shorebird community in the Mondego estuary, Portugal. Waterbirds 28:8-18

Martins I, Pardal MA, Lillebø AI, Flindt MR, Marques JC
(2001) Hydrodynamics as a major factor controlling the occurrence of green macroalgal blooms in a eutrophic estuary: a case study on the influence of precipitation and river management. Estuar Coast Shelf Sci 52:165-177

Metzmacher K, Reise K (1994) Experimental effects of tidal flat epistructures on foraging birds in the Wadden Sea. Ophelia 6:217-225

Múrias T, Cabral JA, Marques JC, Goss-Custard JD (1996) Short-term effects of intertidal macroalgal blooms on the macrohabitat selection and feeding behaviour of wading birds in the Mondego estuary (west Portugal). Estuar Coast Shelf Sci 43:677-688

Múrias T, Cabral JA, Lopes RJ, Marques JC (1997) Low-water use of the Mondego estuary (west Portugal) by waders (Charadrii). Ardeola 44:79-91

Múrias T, Cabral JA, Lopes RJ, Marques JC (2002) Effects of eutrophication on waders (Aves, Charadrii) in the Mondego estuary: a multi-level approach. In: Pardal MA, Marques JC, Graça MAS (eds) Aquatic ecology of the Mondego river basin. Global importance of local experience. Imprensa da Universidade de Coimbra, Coimbra, p 527-540

Pardal MA, Marques JC, Metelo I, Lillebø AI, Flindt MR (2000) Impact of eutrophication on the life cycle, population dynamics and production of Ampithoe valida (Amphipoda) along an estuarine spatial gradient (Mondego estuary, Portugal). Mar Ecol Prog Ser 196:207-219

Pardal MA, Cardoso PG, Sousa JP, Marques JC, Raffaelli D (2004) Assessing environmental quality: a novel approach. Mar Ecol Prog Ser 267:1-8

R Development Core Team (2003) R: a language and environment for statistical computing. R Foundation for Statistical Computing, Vienna

Raffaelli DG, Hull S, Milne H (1989) Long-term changes in nutrients, macroalgal mats and shorebirds in an estuarine system. Cah Biol Mar 30:259-270

Raffaelli DG, Raven J, Poole L (1998) Ecological impact of green macroalgal blooms. Annu Rev Mar Biol Oceanogr 36:97-125

Reise K, Siebert I (1994) Mass occurrence of green algae in the German Wadden Sea. Dtsch Hydrogr Z (Suppl) 1:171-180

Sousa J (2003) Informação sobre distribuição de efectivos de avifauna para revisão do livro vermelho de vertebrados. Instituto de Conservação da Natureza, Lisbon

Tubbs CR, Tubbs JM (1980) Waders and shelduck feeding distribution in Langstone Harbour, Hampshire. Bird Study 27:239-248

Valiela I, McClelland J, Hauxwell J, Behr PJ, Hersh D, Foreman K (1997) Macroalgal blooms in shallow estuaries: control and ecophysiological and ecosystem consequences. Limnol Oceanogr 45:1105-1118

Verdelhos T, Neto JM, Marques JC, Pardal MA (2005) The effect of eutrophication abatement on the bivalve Scrobicularia plana. Estuar Coast Shelf Sci 63:261-268

Webster MS, Marra PP, Haig SM, Bensch S, Holmes RT (2002) Links between worlds: unraveling migratory connectivity. Trends Ecol Evol 17(2):76-83

Wetlands International (2002) Waterbird population estimates, 3rd edn. Wetlands International Global Series 12, Wetlands International, Wageningen

Wood SN, Augustin NH (2002) GAMs with integrated model selection using penalized regression splines and applications to environmental modelling. Ecol Model 157: $157-177$

Submitted: August 23, 2004; Accepted: February 27, 2006

Proofs received from author(s): September 14, 2006 